\title{
PERSEPSI TERHADAP BODY IMAGE ANTARA SISWI YANG MENGGUNAKAN JILBAB DENGAN SISWI YANG TIDAK MENGGUNAKAN JILBAB (Studi Komparatif di SMK Tirta Sari Surya Jakarta Timur)
}

\author{
Syifa Khaeriyah ${ }^{1}$ \\ Dra. Michiko Mamesah, M. Psi \\ Dr. Awaluddin Tjalla ${ }^{3}$
}

\begin{abstract}
Abstrak
Penelitian ini bertujuan untuk melihat bagaimana persepsi terhadap body image antara siswi yang menggunakan jilbab dengan siswi yang tidak menggunakan jilbab di SMK Tirta Sari Surya Jakarta Timur dan melihat apakah terdapat perbedaan persepsi terhadap body image antara siswi yang menggunakan jilbab dengan siswi yang tidak menggunakan jilbab. Metode yang digunakan adalah studi komparatif. Sampel dalam penelitian ini berjumlah 120 siswi, yang terdiri atas 60 siswi yang menggunakan jilbab dan 60 siswi yang tidak menggunakan jilbab. Pengumpulan data dilakukan dengan menggunakan instrumen body image yaitu Multidimentional Body Self Related Questtionaire (MBSRQ) yang dikemukakan oleh Thomas F. Cash. Berdasarkan hasil pengujian hipotesis dengan menggunakan teknik analisis Uji Mann-Whitney U-Test, diperoleh hasil nilai asymp. Sig =0.026, hipotesis penelitian diuji pada taraf signifikansi atau dengan tingkat kesalahan sebesar 5\%, maka Nilai Asymp. Sig $=0.026<$ nilai signifikasi . Dapat dikatakan bahwa terdapat perbedaan persepsi terhadap body image antara siswi yang menggunakan jilbab dengan siswi yang tidak menggunakan jilbab.
\end{abstract}

Kata Kunci : Body image, Jilbab, Remaja

\section{Pendahuluan}

Setiap manusia sebagai makhluk pribadi mengalami proses perkembangan dan pertumbuhan dalam hidupnya, baik secara fisik maupun psikologis. Mengalami beberapa permasalahan, baik permasalahan pribadi maupun sosial. Tugas-tugas perkembangan merupakan suatu proses yang menggambarkan perilaku kehidupan sosiopsikologis manusia pada posisi yang harmonis di dalam lingkungan ma- syarakat yang lebih luas dan kompleks. Proses tersebut merupakan tugas-tugas perkembangan fisik dan psikis yang harus dipelajari, dijalani, dan dikuasai oleh setiap individu. Mulai dari masa kanak-kanak, remaja sampai pada masa dewasa dan usia tua. Pada setiap masanya, individu akan menemukan hal-hal baru yang akan menuntunnya ke masa selanjutnya. Perkembangan fisik berlangsung dengan cepat yang menyebabkan remaja menjadi sangat memperhatikan tubuh mereka dan membangun citra tubuh atau

\footnotetext{
Mahasiswa Jurusan Bimbingan dan Konseling FIP UNJ, syifakhaeriyah03@gmail.com

Dosen Bimbingan dan Konseling FIP UNJ, michikomamesah@yahoo.com

Dosen Bimbingan dan Konseling FIP UNJ, awaluddintjalla@yahoo.com
} 
body image. Body image merupakan persepsi individu dalam mengevaluasi dan menilai penampilan fisik berdasarkan gambaran ideal penampilan yang diinginkan. Awalnya, penilaian body image didominasikan oleh pencarian "body schema" (bagan tubuh), yaitu penelitian yang berisikan informasi mengenai fisik diri, khususnya pada wanita. Setiap individu memiliki persepsi yang berbeda-beda mengenai body image diri, sesuai dengan cara mempersepsikan tubuhnya dengan konsep ideal yang dimilikinya pada pola kehidupan setempat dan dalam hubungannya dengan cara orang lain menilai tubuhnya. Pakaian menjadi salah satu penunjang penampilan seseorang mempersepsikan dirinya. Salah satu cara berpakaian yang berkaitan dengan nilai agama dan yang sering menjadi pusat perhatian adalah mengenakan jilbab, di sekolah banyak ditemui siswi yang telah menggunakan jilbab. Jilbab bagi siswi yang menggunakannya merupakan pakaian penunjang penampilannya. Banyak faktor yang menjadi alasan siswi yang menggunakan jilbab.

Dari siswi yang menggunakan jilbab dengan siswi yang tidak menggunakan jilbab masih banyak ditemui permasalahan mengenai body image, hal ini dikarenakan siswi tersebut masih berada pada fase perkembangan yang sama. Beberapa siswi yang diwawancarai merasa tidak puas dengan bentuk tubuh yang dimilikinya sehingga melakukan berbagai cara untuk mendapatkan tubuh yang ideal sesuai dengan persepsinya. Salah satu caranya yaitu dengan melakukan diet. Hal ini akan berpengaruh pada psikis siswi bahkan berpengaruh dengan kesehatan siswi. Dengan adanya permasalahan ini guru BK dapat melakukan berbagai cara contohnya memberikan layanan informasi guna memberikan pengarahan kepada siswi bahwa mereka berada pada fase perkembangan yang terdapat perubahan pada fisik siswi, menerima body image secara lebih positif dan untuk siswi yang menggunakan jilbab diarahkan agar lebih konsisten dengan pakaian yang digunakannya dan memperdalam ilmu agamanya sehingga dapat memantapkan niat untuk menggunakan jilbab dengan pikiran dan persepsi yang lebih positif terhadap body image nya.

\section{Kajian Teori \\ Body Image}

Istilah body image pertama kali diungkapkan oleh Paul Schilder yang menyatakan bahwa body image sebagai gambaran mengenai tubuh kita yang mana terbentuk dari pikiran kita sendiri. Rudd dan Lennon mengartikan body image sebagai gambaran pikiran yang kita miliki tentang tubuh kita. Gambaran pikiran ini meliputi dua komponen, yaitu komponen perseptual (ukuran, bentuk, berat, karakteristik, gerakan, dan performasi tubuh) dan komponen sikap (apa yang kita rasakan tentang tubuh kita dan bagaimana perasaan tersebut mempengaruhi tingkah laku) (Thomas F. Cash, 2002: 7). "Body image is people's, feelings and thoughts about their physical appearance" (Cash \&Pruzinsky, 2002). Hal ini menunjukkan bagaimana seseorang berbicara tentang tubuhnya dan bagaimana seseorang melihat orang lain atau masyarakat menilai penampilannya. Body image terdiri dari berbagai dimensi yang saling mempengaruhi, meliputi persepsi, afeksi dan evaluasi serta behavioral. Faktor yang mempengaruhi body image, yaitu : Faktor budaya, faktor media massa, faktor keluarga, dan faktor teman sebaya.

\section{Jilbab}

Secara terminologi, jilbab dimaknai sebagai kerudung lebar yang digunakan perempuan muslimah untuk menutupi kepala dan leher hingga dada (Kamus Besar Bahasa Indonesia). Jilbāb (Arab) adalah busana muslim terusan panjang menutupi seluruh badan kecuali tangan, kaki dan wajah yang biasa dikenakan oleh para wanita muslim.

\section{Remaja}

Remaja dalam Bahasa Inggris disebut adolecense, istilah ini berasal dari kata latin adolescere (kata benda adolescentia yang berarti remaja) yang berarti "tumbuh" atau "tumbuh menjadi dewasa".(E. Hurlock, 2000:206) Kemudian diperjelas oleh Mus (1968) dalam buku karangan Prof. Dr. Sarlito, yang mengatakan bahwa kematangan dalam hal ini tidak hanya berarti kematangan fisik, tetapi juga kematangan sosial-psikologis (Sarlito, 2008:8) 
Erikson melihat remaja sebagai periode latensi sosial, seperti ia melihat usia sekolah sebagai periode latensi seksual. Walaupun remaja berkembang secara seksual dan kognitif, di sebagian besar masyarakat barat mereka diperbolehkan untuk menunda komitmen jangka panjangnya terhadap suatu pekerjaan, pasangan seksual, atau filosofi adaptif akan kehidupan. Mereka diizinkan untuk mengalami berbagai cara dan untuk mencoba peran-peran serta keyakinan baru sambil mencari-cari untuk mencapai rasa ego identitas. Jadi, remaja adalah fase adaptif dari perkembangan kepribadian atau periode mencoba-coba (Jes \& Gregory Feist, 2000:303)

\section{Metode Penelitian}

Penelitian ini dilakukan di SMK Tirta Sari Surya Jakarta Timur dengan sampel sebanyak 120 orang siswi yang terdiri dari 60 orang siswi yang menggunakan jilbab dan 60 orang siswi yang tidak menggunakan jilbab. Penelitian ini dilaksanakan pada bulan Oktober 2014 sampai November 2014 dengan menggunakan metode studi komparatif. Tujuan penelitian komparatif adalah dipakai untuk menguji teori sehingga ditemukan perbedaan dan kesamaan. Penelitian komparatif merupakan bagian dari penelitian kuantitatif.

Penelitian ini menggunakan satu variabel, yaitu body image, dan menggunakan dua subjek penelitian, yaitu siswi yang menggunakan jilbab dan siswi yang tidak menggunakan jilbab. Pengukuran pada penelitian ini dilakukan dengan menggunakan instrumen MBSRQ (Multidimentional Body Self Related Questtionaire) yang telah diadaptasi ke dalam bahasa Indonesia. Instrumen ini memiliki 34 item pernyataan yang valid dan memiliki koefisien reliabilitas sebesar 0.990, hal tersebut menyimpulkan bahwa instrument tersebut layak dan dapat dipergunakan dalam penelitian ini. Teknik analisis data yang digunakan dalam menguji hipotesis pada penelitian ini adalah Mann-Whitney U-Test untuk membandingkan dua kelompok yaitu kelompok siswi yang menggunakan jilbab dengan siswi yang tidak menggunakan jilbab.

\section{Hasil dan Pembahasan}

Berdasarkan hasil perhitungan dengan meng- gunakan teknik analisis Uji Mann-Whitney U-Test yang dilakukan dengan aplikasi Statistic Product and Service Solution (SPSS) versi 16.0 for Windows, diperoleh nilai Asymp. Sig $=0.026$, hipotesis penelitian diuji pada taraf signifikansi $\alpha=0.05$ atau dengan tingkat kesalahan sebesar 5\%, maka Nilai Asymp. Sig $=0.026<$ nilai signifikasi $\alpha=$ 0.05 . Hal ini menyatakan bahwa, hipotesis penelitian yang diuji terdapat perbedaan, tetapi tidak terlalu signifikan terhadap body image siswi yang menggunakan jilbab dan yang tidak menggunakan jilbab. Pada siswi yang menggunakan jilbab mendapatkan skor lebih besar daripada siswi yang tidak menggunakan jilbab, namun perbedaan tersebut tidak terlalu signifikan, dan dapat dikatakan bahwa siswi yang menggunakan jilbab dan siswi yang tidak menggunakan jilbab tidak mempunyai banyak pengaruh dalam mempersepsikan body imagedirinya, melainkan lingkungan dan cara pandang individu itu sendiri yang mampu mengubah persepsi yang ada pada diri individu. Maka hal tersebut dapat mempengaruhi pada kehidupan pribadi individu.

Terdapat data kategorisasi persepsi terhadap body image siswi yang menggunakan jilbab. Di bawah ini terdapat rincian tabel kategorisasi siswi yang menggunakan jilbab.

\begin{tabular}{|c|c|c|}
\hline Kategorisasi & Jumlah Responden & Persentase \\
\hline Tinggi: $>128.15$ & 8 siswi & $13.3 \%$ \\
\hline Sedang: $101.8-127.155$ & 47 siswi & $78.3 \%$ \\
\hline Rendah $:<100.8$ & 5 siswi & $8.3 \%$ \\
\hline
\end{tabular}

Dapat terlihat bahwa persentase tertinggi pada siswi yang menggunakan jilbab sebagian besar berada pada kategori sedang. Makna dari tinggi, sedang, dan rendah pada instrumen body image yaitu, pada siswi yang menggunakan jilbab berada pada kategori tinggi yaitu, siswi dengan menggunakan jilbab siswi dapat terlihat lebih fashionable, lebih percaya diri dengan apa yang dikenakan, dengan trend jilbab saat ini siswi dapat mengkreasikan penampilannya dengan semaksimal mungkin. Untuk siswi yang menggunakan jilbab pada kategori sedang, diartikan siswi tersebut dapat menutupi kekurangannya dengan menggunakan jilbab, dengan menggunakan jilbab siswi dapat merasa lebih percaya diri lagi, dan siswi yang menggunakan jilbab dengan kategori rendah yaitu siswi yang mempunyai body im- 
age negatif yang merasa tidak puas dengan keadaan tubuh yang dimiliki, jilbab yang dikenakan semata-mata mengikuti teman-teman yang ada di sekitarnya. Siswi dengan kategori rendah membandingbandingkan bentuk tubuhnya dengan bentuk tubuh yang dimiliki orang lain.

Terdapat data persepsi terhadap body image siswi yang tidak menggunakan jilbab di bawah ini terdapat rincian tabel kategorisasi siswi yang tidak menggunakan jilbab sebagai berikut:

\begin{tabular}{|c|c|c|}
\hline Kategorisasi & Jumlah Responden & Persentase \\
\hline Tinggi: $>123.5$ & 7 siswi & $11.7 \%$ \\
\hline Sedang: $100.7-122.5$ & 48 siswi & $80.0 \%$ \\
\hline Rendah: $<99.7$ & 5 siswi & $8.3 \%$ \\
\hline
\end{tabular}

Dapat terlihat bahwa persentase tertinggi pada siswi yang tidak menggunakan jilbab sebagian besar berada pada kategori sedang. Makna dari tinggi, sedang, dan rendah pada intstrumen body image yaitu, pada siswi yang tidak menggunakan jilbab berada pada kategori tinggi siswi menerima keadaan tubuh atau body image secara positif, siswi merasa puas dengan bentuk tubuh yang dimiliki. Melakukan perawatan di salon membuat siswi lebih percaya diri dengan keadaan tubuhnya. Untuk siswi yang tidak menggunakan jilbab pada kategori sedang diartikan siswi tersebut telah menerima body image dirinya dengan positif meskipun terdapat bagian tubuh atau bentuk tubuhnya yang kurang memuaskan tetapi tidak menjadi suatu permasalahan bagi pribadinya masing-masing. Pada bagian tubuh yang kurang memuaskan siswi melakukan perawatan untuk menutupi kekurangan pada keadaan tubuhnya. Pada siswi yang tidak menggunakan jilbab dengan kategori rendah yaitu siswi yang mempunyai body image negatif yang merasa tidak puas dengan keadaan tubuh yang dimiliki, kebanyakan dari mereka membanding - bandingkan tubuhnya dengan orang lain dan melakukan sesuatu seperti diet agar mendapatkan tubuh yang ideal. Seseorang yang melakukan diet yang berlebih akan terus menerus tidak merasa puas dengan keadaan tubuh yang dimilikinya.

\section{Pembahasan}

Berdasarkan hasil pengujian hipotesis, terdapat perbedaan tetapi kurang signifikan antara persepsi terhadap body image siswi yang menggunakan jilbab dengan siswi yang tidak menggunakan jilbab pada siswi kelas XI AP dan XII AP dan AK di SMK Tirta Sari Surya Jakarta Timur, Berdasarkan hasil penghitungan dengan menggunakan SPSS, nilai Asymp. Sig sebesar 0.026 yang berarti nilai probabilitas lebih kecil dari nilai signifikansi $\alpha 0.05$, dengan demikian dapat disimpulkan bahwa terdapat perbedaan persepsi terhadap body image antara siswi yang menggunakan jilbab dengan siswi yang tidak menggunakan jilbab.

Berikut ini terdapat tabel perbedaan skor dan persentase pada masing-masing sub skala body image siswi yang menggunakan jilbab dengan siswi yang tidak menggunakan jilbab:

\begin{tabular}{|c|c|c|}
\hline SUB SKALA & Berjilbab & Tidak Berjilbab \\
\hline Orientasi Penampilan & $21 \%$ & $20 \%$ \\
\hline Evaluasi Penampilan & $38 \%$ & $38 \%$ \\
\hline Kecemasan Menjadi gemuk & $10 \%$ & $10 \%$ \\
\hline Persepsi Terhadap Ukuran Tubuh & $6.00 \%$ & $5.80 \%$ \\
\hline Kepuasan Terhadap Bagian Tubuh & $25 \%$ & $25 \%$ \\
\hline
\end{tabular}

Dari tabel persentase kelompok responden mengenai persepsi terhadap body image antara siswi yang menggunakan jilbab dengan siswi yang tidak menggunakan jilbab, berdasarkan sub skala body image terlihat tidak jauh antara persentase siswi yang menggunakan jilbab dengan siswi yang tidak menggunakan jilbab. Hal ini dapat disimpulkan bahwa persepsi terhadap body image antara dua kelompok responden ini tidak berbeda jauh yang dikarenakan sebagai remaja, tahap perkembangan psikis dan psikologis mereka berada pada fase yang sama. Mereka pun berada pada lingkungan yang sama sehingga tidak berbeda jauh perbedaan persepsi mereka terhadap body image.

Pada sub skala evaluasi penampilan (Apperarance evaluation) mengukur evaluasi dari penampilan dan kesuluruhan tubuh, apakah menarik atau tidak serta memuaskan dan tidak memuaskan, antara siswi yang menggunakan jilbab dengan siswi yang tidak menggunakan jilbab menunjukkan persentase yang sama yaitu $38 \%$. Karena pada sub skala ini siswi yang berjilbab maupun tidak berjilbab memperhatikan penampilan dirinya saat memakai pakaian, apakah pakaian yang digunakan dapat membuat dirinya menarik atau memuaskan dikarenakan setiap perempuan ingin terlihat menarik di hadapan 
orang lain atau lingkungan dimana ia berada.

Pada sub skala orientasi penampilan (Appearance orientation) perhatian individu terhadap penampilan dirinya dan usaha yang dilakukan untuk memperbaiki dan meningkatkan penampilan dirinya, siswi yang menggunakan jilbab dengan siswi yang tidak menggunakan jilbab terdapat perbedaan persentase tetapi perbedaan itu hanya $1 \%$. Setiap siswi atau remaja putri ingin terlihat menarik dengan penampilannya oleh karena itu perbaikan dan peningkatan penampilannya selalu diperhatikan. Hal ini baik dilakukan untuk selalu memperbaiki penampilannya bukan hanya fisik tetapi didukung oleh perilaku, pikiran yang positif sehingga dapat menjadi individu yang lebih positif. Orang lain yang akan melihat dirinya akan merasakan hal yang positif pula.

Pada sub skala kepuasan terhadap bagian tubuh (Body area satisfaction) mengukur kepuasan terhadap bagian tubuh secara spesifik seperti wajah, rambut, tubuh bagian bawah, tubuh bagian tengah, tubuh bagian atas, dan penampilan secara keseluruhan. Antara siswi yang menggunakan jilbab dengan siswi yang tidak menggunakan jilbab menunjukkan persentase yang sama yaitu $25 \%$, diantara dua kelompok responden yang diteliti sebagian besar memperhatikan keseluruhan bentuk dan ukuran tubuhnya hal ini wajar bagi seorang perempuan yang mengutamakan penampilan dan akan lebih baik jika pikiran dan perbuatan juga diperbaiki sehingga akan menimbulkan keseluruhan diri yang positif penampilan luar maupun dalam diri individu.

Pada sub skala kecemasan menjadi gemuk (Overweight preoccupation) mengukur kecemasan terhadap kegemukan, kewaspadaan individu terhadap berat badan, kecenderungan melakukan diet untuk menurunkan berat badan dan membatasi pola makan. Antara siswi yang menggunakan jilbab dengan siswi yang tidak menggunakan jilbab menunjukkan persentase yang sama yaitu sebesar $10 \%$. Siswi yang merasa cemas dengan bertambahnya berat badan dan melakukan diet yang tidak sehat atau berlebih untuk menurunkan berat badan akan menimbulkan body image yang negatif karena selalu khawatir akan kenaikan berat badannya. Hal ini harus diminimalisir terutama pengawasan keluarga yaitu orangtua yang harus memberikan pengarahan terhadap anaknya agar tidak salah dalam cara- cara menurunkan berat badan dan berfikiran positif dengan menerima mensyukuri keadaan bentuk tubuh yang dimilikinya. Pada sub skala ini menunjukkan body image individu yang rendah yaitu tidak menerima bentuk tubuhnya secara bijaksana. Akibat dari tidak bisa menerima keadaan tubuhnya individu akan terus menerus merasa cemas dengan tubuhnya.

Pada sub skala persepsi terhadap ukuran tubuh (Self-classified weight) persepsi dan penilaian individu terhadap berat badannya, mulai dari kekurangan berat badan sampai kelebihan berat badan. Antara siswi yang menggunakan jilbab dengan siswi yang tidak menggunakan jilbab terdapat perbedaan presentase yang tidak jauh berbeda hanya sebesar $2 \%$. Sama dengan sub skala kecemasan menjadi gemuk, siswi yang berada pada sub skala ini mempunyai body image yang negatif. Tidak dapat menerima keadaan tubuhnya. Merasa cemas dengan kenaikan atau turunnya berat badan. Orangtua dan guru BK harus memberikan arahan dan pengetahuan yang membuat siswi dapat berfikiran positif dengan keadaan tubuhnya sehingga kecemasan mengenai berat atau ukuran tubuhnya dapat teratasi.

Dari data-data yang diperoleh body image merupakan permasalahan yang cukup banyak ditemui dikalangan remaja khususnya remaja putri. Seperti yang dikemukakan oleh Thomas F. Cash "Body image is people's, feelings and thoughts about their physical appearance" bagaimana individu mempersepsikan tubuh mereka. Membandingkan penilaian orang lain mengenai penampilannya. Body image merupakan bagian dari konsep diri. Body image harus realistis karena semakin seseorang dapat menerima dan menyukai tubuhnya, ia akan lebih bebas dan merasa aman dari kecemasan sehingga harga dirinya akan meningkat. Sikap individu terhadap tubuhnya mencerminkan aspek penting dalam dirinya. Proses pembentukan body image ini dipengaruhi oleh berbagai hal, diantaranya faktor budaya, faktor media massa, faktor keluarga, dan faktor teman sebaya.

Kecantikan jiwa atau inner beauty punya pengaruh besar pada penampilan sehari-hari. Tidak bisa dipungkiri bahwa pandangan pertama yang akan dilihat orang adalah penampilan fisik seperti kulit putih, wajah cantik, pakaian yang modis, maka akan terlihat menarik dan mempesona yang akan mem- 
buat seseorang terlihat dikagumi bukan hanya oleh pria tapi juga perempuan. Sebab baik perempuan maupun pria menyukai keindahan oleh pesona lahiriah yang dimiliki. Namun apa artinya pesona lahiriah jika tidak didukung oleh pesona yang terpancar dari jiwa.

Ketika seorang perempuan atau siswi yang menggunakan jilbab guna menunjang penampilannya dan menjalani perintah agama, alangkah lebih baiknya diselaraskan dengan inner beauty atau kecantikan jiwa, hal tersebut akan lebih terpancarkan lagi jika seorang remaja putri yang menggunakan jilbab jika hati, pikiran, perilaku, dan jiwa nya juga menunjukkan aura positifnya. Hal tersebut membuat pandangan orang lain atau persepsi orang lain melihat dirinya akan terlihat lebih positif pula. Begitupun siswi yang tidak menggunakan jilbab, jika body image-nya positif, pikiran, perilaku, dan jiwanya positif maka akan terlihat menarik dan mempesona yang akan membuat seseorang terlihat dikagumi bukan hanya oleh pria tapi juga perempuan. Sebab baik perempuan maupun pria menyukai keindahan oleh pesona lahiriah yang dimiliki. Namun apa artinya pesona lahiriah jika tidak didukung oleh pesona yang terpancar dari jiwa.

\section{Kesimpulan dan Saran}

Berdasarkan penelitian yang telah dilakukan, terdapat persepsi terhadap body image antara siswi yang menggunakan jilbab dengan siswi yang tidak menggunakan jilbab. Penelitian ini dapat menjadi bahan informasi untuk guru BK dalam memberikan bimbingan klasikal maupun bimbingan kelompok kepada peserta didik di sekolah. Mengadakan konseling kelompok maupun konseling pribadi terhadap peserta didik yang mempunyai permasalahan tentang body image dan mengembangkannya dengan menggunakan pendekatan teknik - teknik konseling contohnya konseling CBT (Cognitive Behavioral Therapy). Implikasi penelitian ini adalah menjadi tambahan infor- masi bagi guru BK mengenai persepsi terhadap body image siswi yang menggunakan jilbab dengan siswi yang tidak menggunakan jilbab, dan dapat menindaklanjuti para siswi yang mempunyai permasalahan tentang body image dengan memberikan bimbingan kelompok maupun konseling kelompok sehingga siswi dapat memahami body image yang lebih positif dan juga dapat menghargai dirinya dan dapat menerima keadaan fisiknya lebih positif. Peserta didik yang menggunakan jilbab disarankan untuk mendalami agama dengan lebih dalam lagi sehingga dapat konsisten dengan pilihan nya menggunakan jilbab. Sementara bagi peserta didik yang belum konsisten menggunakan jilbab diharapkan memperdalam lagi ilmu agama, meluruskan niat dan memahami lagi manfaat dari jilbab itu sendiri.

\section{Referensi}

Aurellie Untas Et all. Psychometric Properties of The French Adaptation of MBSRQ. http://psychologie. univ.fcomte.fr/download/sectionpsychologie/document/pdf/xabi.pr.pdf

Cash, Thomas F \& Thomas Pruzinsky. 2002. Body image a Handbook of Theory, Research and Clinical Practice. New York: Guilford Press

Cash. Thomas F. 2000. The Multidimentional Body-Self Relation Questionnaire: MBSRQ User's Manual (3rd Revision). Norlfok: Old Dominion University

Depdiknas, Penataan Pendidikan Profesional Konselor dan Layanan Bimbingan Konseling dalam Jalur Pendidikan Formal. 2009. Jakarta: Departemen Pendidikan Nasional

Grogan, Sarah. 2008. Body image: Understanding Body Dissatisfaction in Men, Women and Children. New York: Routledge

Hurlcok. E. B. 2000. Psikologi Perkembangan, Edisi kelima. Jakarta: Erlangga

Santrock, Adolescence. 2003. Jakarta: Penerbit Erlangga

Thompson, J.K. 2002. Exacting Beauty (Theory, Assesment, and Treatment of Body image Disturbance. New York: Guildfort 